\title{
Soot Formation and Oxidation in Laminar Flames
}

\author{
C. H. Kim ${ }^{*}$ \\ Purdue University, West Lafayette, Indiana 47907, USA \\ F. $\mathrm{Xu}^{\dagger}$ \\ University of Central Florida, Orlando, Florida 32816, USA \\ P. B. Sunderland \\ University of Maryland, College Park, 20742, USA \\ A. M. El-Leathy ${ }^{\S}$ \\ Helwan University, Cairo, Egypt \\ and \\ G. M. Faeth ${ }^{* *}$ \\ University of Michigan, Ann Arbor, Michigan 48109, USA
}

\begin{abstract}
The flame and soot structure, including soot primary particle nucleation, surface growth and oxidation properties, of 6 premixed and 20 diffusion flames were studied experimentally for various fuels, at temperatures of 1400-2350 K and at pressures of 13-811 kPa (0.1-8.0 atm). Measurements were made along the axes of flames with the reactants at normal temperature $(300 \mathrm{~K})$. The following properties were measured as a function of distance from the burner exit: soot concentrations by deconvoluted laser extinction, soot temperatures by deconvoluted multiline emission, soot structure by thermophoretic sampling and analysis using transmission electron microscopy (TEM), concentrations of major stable gas species by isokinetic sampling and gas chromatography, concentrations of radial species $(\mathrm{H}, \mathrm{OH}, \mathrm{O})$ by deconvoluted $\mathrm{Li} / \mathrm{LiOH}$ atomic absorption, and flow velocities by laser velocimetry. The measurements were analyzed to determine local soot surface growth, oxidation and nucleation rates, as well as local flame properties that are thought to affect these rates. The measurements of soot surface growth rates (corrected for soot surface oxidation) were consistent with the measurements in laminar premixed and diffusion flames involving a variety of hydrocarbons at variable pressure. In addition, the growth rates from all the available flames were in good agreement with each other and with existing hydrogenabstraction/carbon-addition (HACA) soot surface growth mechanisms available in the literature yielding values of steric factors on the order of unity, as expected. Measurements of early soot surface oxidation rates (corrected for soot surface growth and prior to consumption of $70 \%$ of the maximum mass of the primary soot particles) in laminar diffusion flames were consistent with all flames regardless of flame types, fuels, temperatures and pressures. The soot surface oxidation rates from all available flames could be explained by reaction with $\mathrm{OH}$, having a collision efficiency of 0.12 , and supplemented to only a minor degree by direct soot surface oxidation by $\mathbf{O}_{2}$.
\end{abstract}

* Research Associate, Mechanical Engineering, 500 Allison Rd. West Lafayette, IN 47907, E-mail: kimch@purdue.edu, AIAA member. Corresponding author.

${ }^{\dagger}$ Assistant Professor, Material and Aerospace Engineering, AIAA member.

* Assistant Professor, Department of Fire Protection Engineering, AIAA member.

$\S$ Assistant Professor, Mechanical Power Engineering Department, Helwan University, Cairo, Egypt.

**A.B.Modine, University Distinguished Professor, Department of Aerospace Engineering, Fellow AIAA. 


\section{Nomenclature}

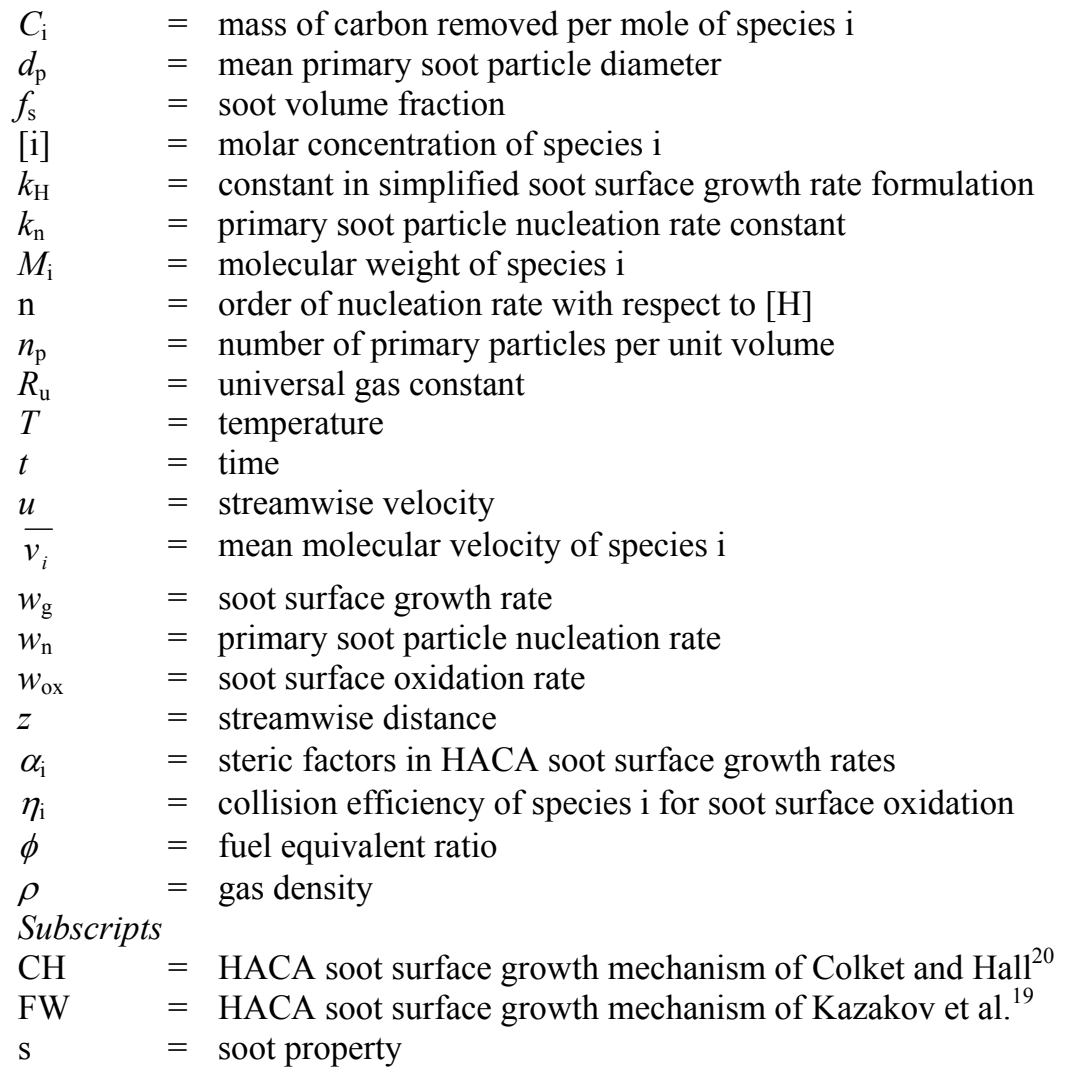

\section{Introduction}

SOOT is a dominant feature of hydrocarbon-fueled nonpremixed (diffusion) flames that affects flame reaction mechanisms, transport properties and structure. Flame-generated soot is also of interest for a number of other reasons: it is a harmful pollutant, ${ }^{1}$ it is responsible for continuum radiation emissions that promote the growth and spread of unwanted fires, ${ }^{2}$ it is responsible for the emission of carbon monoxide from flames which in turn causes most of the deaths in unwanted fires, ${ }^{3,4}$ it primarily generates the heat in operating combustors and reduces their durability and life, ${ }^{5}$ it is twice as potent as carbon dioxide in raising surface air temperatures ${ }^{6-8}$ causing both local warming ${ }^{9}$ and snow/ice albedo, ${ }^{10}$ and the complexities of soot chemistry are a major impediment to the development of computational combustion. Motivated by these observations, the investigation in this laboratory has been sought extensively covering the mechanisms of soot formation that includes nucleation, surface growth and surface oxidation of the primary soot particles.

Earlier studies of the structure and soot surface reaction properties of laminar flames have been reviewed in several articles. ${ }^{11-14}$ Motivated by these studies, the initial work conducted in this laboratory ${ }^{15-17}$ aimed to develop and evaluate mechanisms of soot surface growth. Unfortunately, the measurements did not provide information about $\mathrm{H}$ concentrations needed by the theories. Concentrations of $\mathrm{H}$ were found during the subsequent works so that the measurements could be used to evaluate the hydrogen-abstraction/carbon-addition (HACA) soot surface growth mechanisms in the literature. ${ }^{18-20}$

Soot surface oxidation in laminar premixed flames was studied using the collision efficiency of potential oxidation species. ${ }^{21,22}$ Classical expression of Nagle and Strickland-Constable, ${ }^{23}$ which was confirmed later, ${ }^{24}$ was also examined for $\mathrm{O}_{2}$ oxidation in the present laminar flames. The study showed that soot surface oxidation in laminar premixed flames was dominated by the reaction of the soot surface with $\mathrm{OH}$ and could be correlated effectively by estimating the oxidation rate due to $\mathrm{O}_{2}$ using Nagle and Strickland-Constable oxidation expression. ${ }^{23}$ This finding is also in fair agreement with earlier measurements of soot surface oxidation rates by $\mathrm{OH}$ in diffusion flames at atmospheric pressure. ${ }^{25,27}$

The investigation conducted in this laboratory sought to improve understanding of the structure and soot formation and surface reaction properties of laminar premixed and diffusion flames for a wide ranges of fuel types, 
temperature and pressure, using an arguably the most complete suite of experimental techniques. In addition, the existing HACA soot surface growth mechanisms were examined. This paper summarizes the results obtained by the efforts in this laboratory to investigate soot formation problems for last two decades.

\section{Experimental Methods}

\section{A. Apparatus}

\section{Premixed Flames}

The same experimental apparatus was used for the studies that considered the structure and surface reaction properties of soot within laminar premixed flames. ${ }^{28-30}$ The premixed flames were produced by a $60 \mathrm{~mm}$ diameter water-cooled porous-plate laminar flat-flame burner (McKenna Products, Inc., high-pressure shroud model) directed vertically upward at atmospheric pressure. The reactant mixture at the burner exit was surrounded by a 6 $\mathrm{mm}$ wide annular nitrogen coflow to eliminate the peripheral diffusion flames that are present when fuel-rich premixed flames are burned in room air. The flames were stabilized by impinging the burner flow on a flat plate having a $30 \mathrm{~mm}$ diameter hole centered on the axes of the flames, $32 \mathrm{~mm}$ above the burner exit. The flames were surrounded by layers of screens and a plastic enclosure in order to avoid flow disturbances from drafts in the room.

The reactant stream was mixed using rotameters calibrated by wet-test meters to control reactant concentrations. After metering, the reactant stream passed through a line having a length-to-diameter ratio of roughly 1000 to obtain a homogeneous premixed reactant flow at room temperature at the burner exit. Combustion products from the test flames were removed using the laboratory exhaust system. The burner was cooled with water at room temperature $(294 \pm 2 \mathrm{~K})$ that had a sufficiently large flow rate so that the temperature rise of the coolant passing through the burner was negligible. Finally, the burner could be traversed in the horizontal and vertical directions in order to accommodate rigidly-mounted optical instruments.

\section{Diffusion Flames}

Two different test arrangements were used for the studies that considered the structure and the surface reaction properties of laminar diffusion flames: one for studies of laminar diffusion flames at atmospheric pressure, ${ }^{31-33}$ and one for studies of laminar diffusion flames at pressures of 13-811 kPa (0.1-8.0 atm). ${ }^{34,35}$ The atmospheric pressure burner was uncooled and consisted of a $34.8 \mathrm{~mm}$ diameter inner port for the fuel stream and a $60 \mathrm{~mm}$ diameter coannular outer port for the oxidizer stream, both directed vertically upward. The flame was surrounded by layers of screens and a plastic enclosure in order to avoid flow disturbances from drafts in the room. The fuel and oxidizer streams were independently mixed, using rotameters calibrated by wet-test meters to control their compositions, and then passed through lines having length-to-diameter ratios of roughly 1000 in order to obtain homogeneous reactant streams at room temperature at the burner inlet. Combustion products from the test flames were removed using the laboratory exhaust system. Finally, the burner could be traversed in the horizontal and vertical directions in order to accommodate rigidly-mounted optical instruments.

The variable pressure burner was uncooled and consisted of a $3.3 \mathrm{~mm}$ diameter inner port for the fuel stream, directed vertically upward and surrounded by a slow concentric flow of air. The flames burned along the axis of a vertical cylindrical windowed chamber having a diameter and length of $300 \mathrm{~mm}$. The top and bottom of the chamber consisted of porous plates that separated the flame chamber from plenum chambers for air inflow and exhaust outflow and provided a uniform distribution of air flow over the chamber cross section. The reactant flow rates of the fuel stream were measured with rotameters and after mixing were passed through a line having a lengthto-diameter ratio of roughly 1000 in order to obtain a homogeneous fuel stream at room temperature at the burner exit. The coflowing air stream was also measured with a rotameter. All rotameters were calibrated by wet-test meters. The exhaust flow was removed from the windowed chamber using a vacuum pump. The flames were ignited by a hot wire that could be retracted from the burner exit once ignition was complete. The entire test chamber could be traversed in the vertical and horizontal directions in order to accommodate rigidly mounted optical instruments.

\section{B. Instrumentation}

Measurements in the premixed and diffusion flames were limited to the axes of the flames and were similar for all the studies to be considered, ${ }^{28-35}$ as follows: Soot volume fractions were measured by deconvoluting laser extinction measurements at a visible wavelength of $632.8 \mathrm{~nm}$ for chord-like paths through the flames. This data was reduced using the refractive indices of Dalzell and Sarofim, ${ }^{36}$ of which values have recently been confirmed by 
Krishnan et al. ${ }^{37,38}$ The experimental uncertainties (95\% confidence) of soot volume fractions are estimated to be smaller than $10 \%$ for soot volume fractions greater than $0.02 \mathrm{ppm}$, increasing inversely proportional to the soot volume fraction for smaller values.

Primary soot particles are small, generally having diameters smaller than $50 \mathrm{~nm}$; therefore, soot and gas temperatures are essentially the same. ${ }^{31,32}$ As a result, soot (gas) temperatures were measured by deconvoluting spectral radiation intensities for continuum radiation from soot for chord-like paths through the flames and computing temperatures at several visible wavelength pairs $(550 / 700,550 / 750,550 / 830,600 / 700,600 / 750,600 / 830$ and $650 / 750 \mathrm{~nm}$ ). Temperature differences between the average and any of the individual line pairs were less than $100 \mathrm{~K}$ and experimental uncertainties $(95 \%$ confidence) of these measurements were less than $50 \mathrm{~K}$. This level of accuracy was adequate because primary soot particle nucleation rates were relatively insensitive to direct effects of temperature, similar to other observations of primary soot particle surface reaction rates. ${ }^{28-34}$

The concentrations of major gas species $\mathrm{N}_{2}, \mathrm{Ar}, \mathrm{H}_{2} \mathrm{O}, \mathrm{H}_{2}, \mathrm{O}_{2}, \mathrm{CO}, \mathrm{CO}_{2}, \mathrm{CH}_{4}, \mathrm{C}_{2} \mathrm{H}_{2}, \mathrm{C}_{2} \mathrm{H}_{4}, \mathrm{C}_{2} \mathrm{H}_{6}, \mathrm{C}_{3} \mathrm{H}_{6}, \mathrm{C}_{3} \mathrm{H}_{8}$, $\mathrm{C}_{6} \mathrm{H}_{6}$ and $\mathrm{Ne}$ (the last being a tracer gas used to estimate effects of radial diffusion of lithium-containing species that were used to find $\mathrm{H}, \mathrm{OH}$ and $\mathrm{O}$ concentrations) were measured by isokinetic sampling (based on flow velocity measurements to be discussed later) and analysis by gas chromatography. Experimental uncertainties (95\% confidence) of these measurements were mainly due to calibration uncertainties and are estimated to be less than 5\% for all species concentrations reported here. Finally, present limits of detection for all these species, using sampling and analysis by gas chromatography, were all smaller than $20 \mathrm{ppm}$ at atmospheric pressure ranging up to $200 \mathrm{ppm}$ at $13 \mathrm{kPa}(0.1 \mathrm{~atm})$, the lowest pressure tested.

Soot structure measurements were carried out by thermophoretic sampling and either TEM or HRTEM, following Dobbins and Megaridis. ${ }^{39}$ Primary soot particles were nearly spherical and monodisperse at given positions in each flame (standard deviations of primary soot particle diameters were less than $10 \%$ ) and experimental uncertainties (95\% confidence) of primary soot particle diameter measurements are estimated to be less than $10 \%$.

Streamwise gas velocities were measured using laser velocimetry based on seeding the flame gases with aluminum oxide particles having nominal diameters of $1000 \mathrm{~nm}$. The experimental uncertainties (95\% confidence) of these measurements were less than $5 \%$, largely based on calibration uncertainties.

Measurements of the concentrations of $\mathrm{H}, \mathrm{OH}$ and $\mathrm{O}$ were carried out using deconvoluted absorption in the visible for chord-like paths through the flames following the $\mathrm{Li} / \mathrm{LiOH}$ atomic absorption technique of Neoh and coworkers. ${ }^{21,22}$ As already noted, corrections for the radial diffusion of the $\mathrm{LiOH}$ seed (and its dissociation products) used for these measurements were found from measurements of the concentrations of a Ne seed placed in the flow, assuming that the mass diffusivities of the lithium-containing species and Ne were similar. Similar to Neoh and coworkers, ${ }^{21,22}$ the determination of $\mathrm{H}$ concentrations was calibrated using a premixed flame as discussed by Xu and Faeth. ${ }^{30}$ Measurements using different initial concentrations of $\mathrm{LiOH}$ seed showed that effects of this seed on flame properties were negligible. Experimental uncertainties $(95 \%$ confidence) of the $\mathrm{H}$ concentration measurements are estimated to be smaller than $30 \%$. Given the concentrations of $\mathrm{H}, \mathrm{O}_{2}, \mathrm{H}_{2}$ and $\mathrm{H}_{2} \mathrm{O}$ in the flow, the concentrations of $\mathrm{OH}$ and $\mathrm{O}$ could be computed assuming partial equilibrium among these species following Neoh and coworkers $^{21,22}$ and using equilibrium constant data from Chase et al. ${ }^{40}$ The experimental uncertainties of $\mathrm{OH}$ and $\mathrm{O}$ concentration measurements were comparable to those of $\mathrm{H}$. Finally, limits of detection of $\mathrm{H}, \mathrm{OH}$ and $\mathrm{O}$ were all smaller than $0.01 \mathrm{ppm}$.

\section{Test Conditions}

The properties of the test flames are briefly summarized in Table 1; they include six (6) premixed flames ${ }^{38-30}$ and twenty (20) diffusion flames, ${ }^{31-35}$ see sources listed in Table 1 for more details about the flame test conditions. The premixed flames consisted of the ethylene/air and methane/oxygen flames at atmospheric pressure considered by Harris and Weiner ${ }^{11}$ and Ramer et al., ${ }^{41}$ respectively.

Table 1. Summary of Primary Soot Particle Surface Reaction Rate Data

\begin{tabular}{|c|c|c|c|c|}
\hline Type & Fuel & Oxidant & No. Flames & Source \\
\hline \multicolumn{5}{|c|}{ Atmospheric pressure: } \\
\hline Premixed & $\mathrm{C}_{2} \mathrm{H}_{4}$ & Air & 3 & [28] \\
\hline Premixed & $\mathrm{CH}_{4}$ & $\mathrm{O}_{2}$ & 3 & {$[30]$} \\
\hline Diffusion & $\mathrm{C}_{2} \mathrm{H}_{2}-\mathrm{N}_{2}$ & Air & 3 & [31] \\
\hline Diffusion & $\mathrm{C}_{2} \mathrm{H}_{4}$ & Air & 1 & [32] \\
\hline Diffusion & $\mathrm{C}_{3} \mathrm{H}_{6}-\mathrm{N}_{2}$ & Air & 1 & [32] \\
\hline Diffusion & $\mathrm{C}_{3} \mathrm{H}_{8}$ & Air & 1 & [32] \\
\hline Diffusion & $\mathrm{C}_{2} \mathrm{H}_{2}-\mathrm{C}_{6} \mathrm{H}_{6}-\mathrm{N}_{2}$ & Air & 3 & [32] \\
\hline Diffusion & $\mathrm{C}_{2} \mathrm{H}_{2}-\mathrm{Ar}$ & $\mathrm{O}_{2}-\mathrm{Ar}$ & 3 & [33] \\
\hline \multicolumn{5}{|c|}{ Pressures of 0.1-1.0 atm: } \\
\hline Diffusion & $\mathrm{C}_{2} \mathrm{H}_{2}-\mathrm{N}_{2}$ & Air & 4 & [34] \\
\hline \multicolumn{5}{|c|}{ Pressures of 1.0-8.0 atm: } \\
\hline Diffusion & $\mathrm{C}_{2} \mathrm{H}_{4}-\mathrm{He}$ & $\mathrm{O}_{2}-\mathrm{He}$ & 4 & [35] \\
\hline
\end{tabular}


The diffusion flames were fueled with a variety of hydrocarbons (acetylene, ethylene, propylene, propane and benzene) burning in either air or $\mathrm{O}_{2} / \mathrm{Ar}$ mixtures at atmospheric pressure. For the diffusion flames at the pressures of 13-101 kPa (0.1-1.0 atm), acetylene/ $\mathrm{N}_{2}$ flames with air coflow were investigated. For the flames at pressures of $101-811 \mathrm{kPa}(1.0-8.0 \mathrm{~atm})$, ethylene/He flames with $\mathrm{O}_{2} / \mathrm{He}$ coflow were studied to suppress the transition to turbulent flame due to high pressure conditions. Finally, acetone contamination of acetylene, a potential difficulty pointed out by Hamins et al. ${ }^{42}$ and Colket et al..$^{43,44}$ is not thought to be a problem for present measurements based on evaluation of this effect for acetylene/air laminar jet diffusion flames at atmospheric pressure. ${ }^{31}$

\section{Results and Discussion}

\section{A. Flame and Soot Structures}

\section{Structure of Soot Aggregates}

A typical TEM photograph of soot samples collected from the diffusion flames at atmospheric pressures is shown in Fig. 1 (a). The soot particles observed during the present investigation were similar to those seen during studies of soot processes in laminar premixed flames. ${ }^{28-30}$ This image was obtained at the maximum soot volume fraction location along the axis of $\mathrm{C}_{2} \mathrm{H}_{2}$-Ar diffusion flame at atmospheric pressure. However, the TEM images of soot particles at other atmospheric flame conditions considered here were qualitatively similar. In general, the TEM images indicated that the soot particles consisted of roughly spherical primary soot particles that had nearly constant diameters (standard deviations of primary soot particle diameters at a given flame conditions were less than $10 \%$, as noted earlier), collected into mass (Hausdorf) fractal objects. ${ }^{45}$ The mean number of primary soot particles per aggregate increased with increasing distance from the burner exit up to the point where oxidation caused the aggregates to break apart, near the end of the soot oxidation region.

\section{Structure of Premixed Flames at Atmospheric Pressures}

Measurements of the structure and the TEM-observable primary soot particle nucleation rate properties of a typical soot-containing laminar premixed flame are illustrated in Fig. 2. This flame was a premixed ethylene/air flame at atmospheric pressure with the reactant stream having concentrations of $15.6 \% \mathrm{C}_{2} \mathrm{H}_{4}$ and $84.4 \%$ air by volume, obtained from the measurements of $\mathrm{Xu}$ et al. ${ }^{28}$ Results for other premixed flames, ${ }^{29,30}$ however, were qualitatively similar. Measurements of temperatures, velocities, soot volume fractions, TEM-observable primary soot particle diameters, the concentrations of major gas species, the concentrations of the radical species $\mathrm{H}$, the number of TEM-observable primary soot particles per unit volume and the rate of formation of TEM-observable primary soot particles per unit volume, are plotted as a function of height above the burner exit in this figure. Corresponding elapsed times found by integrating the velocity measurements are shown at the top of the plot. These elapsed times are relative to the first position where finite soot volume fractions were observed.

Effects of buoyancy were significant for the flame conditions of Fig. 3, as a result, the streamwise velocities in Fig. 2 rapidly increase from burner exit values of roughly $60 \mathrm{~mm} / \mathrm{s}$ to values of roughly $1000 \mathrm{~mm} / \mathrm{s}$ at z=30 mm. These velocity increases slow rates of variation of flame properties with increasing distance because elapsed time

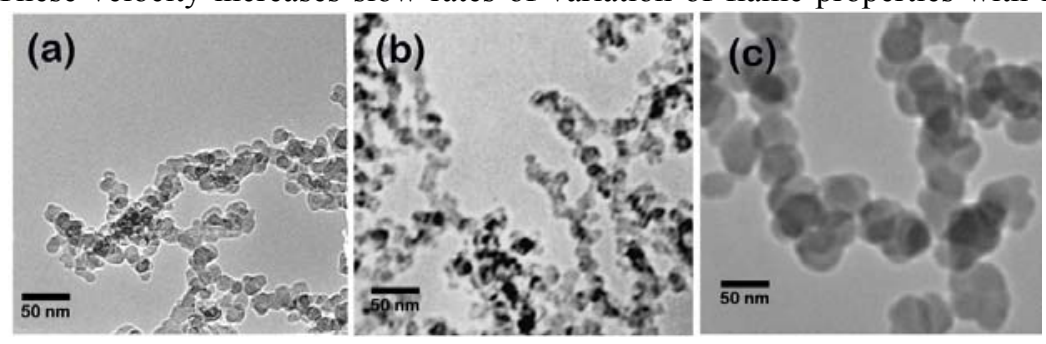

Figure 1. TEM photographs of soot aggregates at maximum soot volume fraction location along the axis of (a) an acetylene $(42 \%$ by volume)-argon-fueled laminar jet diffusion flame burning in an oxygen (48.8\% by volume)-argon coflow at atmospheric pressure, (b) an acetylene $(\mathbf{1 0 0 \% )}$ ) fueled laminar jet diffusion flame burning in air at $13 \mathrm{kPa}(0.125 \mathrm{~atm})$, and (c) an ethylene (10.2 \% by volume)helium-fueled laminar jet diffusion flame burning in an oxygen (31.6\% by volume)-helium coflow at $811 \mathrm{kPa}(8.0 \mathrm{~atm})$. increments are inversely proportional to velocities.

The presence of significant soot concentrations in the premixed flame considered in Fig. 2 is responsible for appreciable continuum radiation heat losses. These heat losses cause the soot temperatures in Fig. 2 to decrease from values of roughly $2000 \mathrm{~K}$ (at $\mathrm{z}=7.5 \mathrm{~mm}$ ) to values of roughly 1500 $\mathrm{K}$ at the highest location where temperatures were measured (at $\mathrm{z}=27.5$ $\mathrm{mm})$. The optical measurements of soot volume fractions for this flame are in excellent agreement with the gravimetric measurements of soot volume fractions for the same flame. ${ }^{46}$ 


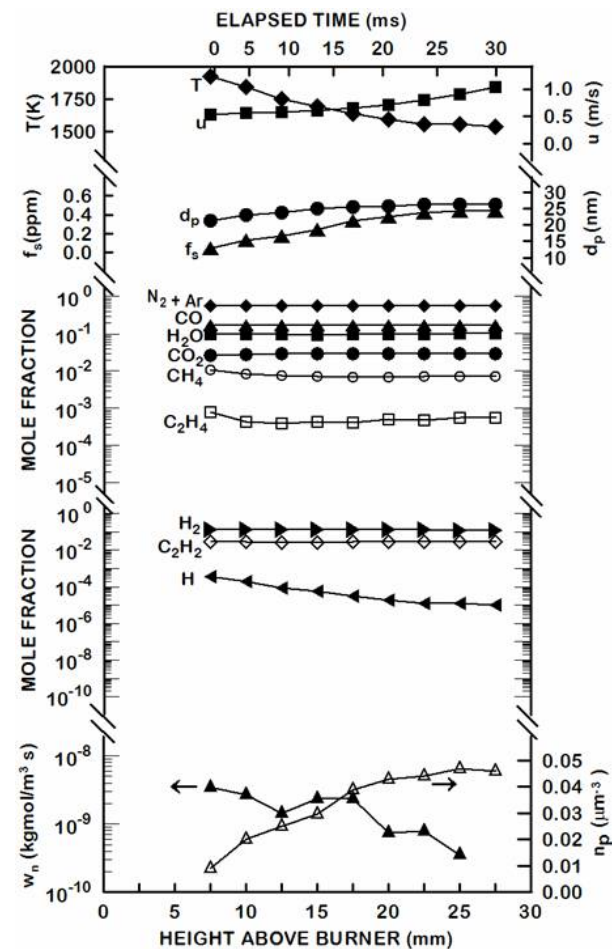

Figure 2. Measured soot, flame and nucleation properties along the axis of an acetylene $(15.6 \%$ by volume)-air laminar jet premixed flame at atmospheric pressure.

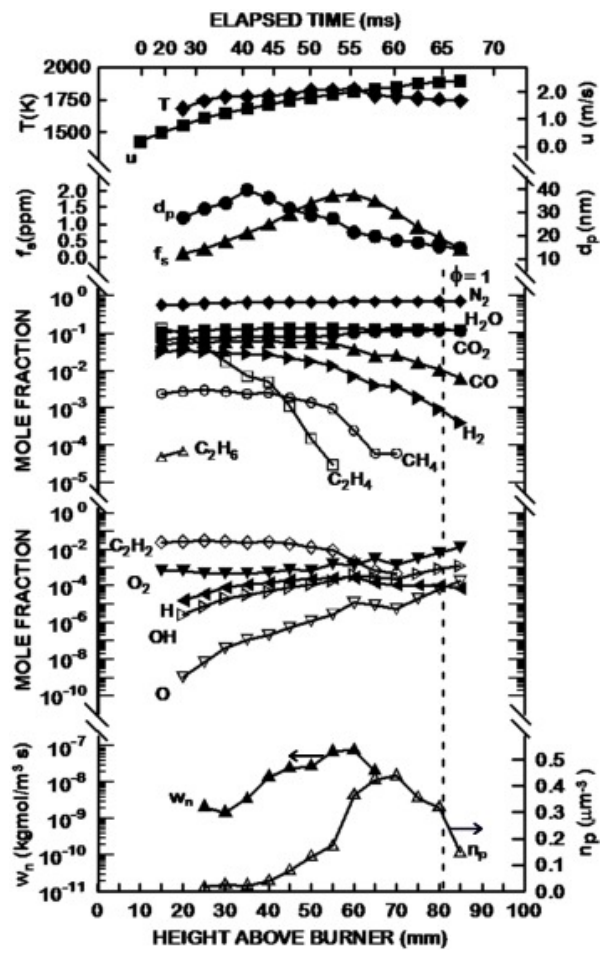

Figure 3. Measured soot, flame and nucleation properties along the axis of an ethylene fueled laminar jet diffusion flame burning in an air coflow at atmospheric pressure.

Finite soot volume fractions are first observed near $z=7.5 \mathrm{~mm}$ for the flame illustrated in Fig. 2. Soot volume fractions subsequently increase for a time but then level off with increasing distance from the burner exit where soot formation and oxidation rates become small; this is a well known trend for soot-containing laminar premixed flames. $^{24,25}$

The measurements of TEM-observable primary soot particle diameters for the flame illustrated in Fig. 2 are in good agreement with TEM-observable primary soot particle diameters measured for the same flame earlier, ${ }^{46}$ using similar methods. The range of the TEM-observable primary soot particle diameter measurements in Fig. 2, corresponds to conditions where soot volume fractions could be measured with acceptable experimental uncertainties, which involves primary particles that were also observable using TEM techniques that have mean diameters generally larger than $10 \mathrm{~nm}$. For the range of the measurements illustrated in Fig. 2, mean TEMobservable primary soot particle diameters increase and then level off with increasing distance from the burner exit, similar to the behavior of soot volume fractions, which is expected behavior if soot formation and oxidation rates become small with increasing distance from the burner exit.

The concentrations of major stable gas species are also plotted in Fig. 2. Where they overlap, the measurements illustrated in Fig. 2 are in good agreement with other observations for the same flame conditions ${ }^{11,32}$ within experimental uncertainties. The concentrations of major stable gas species are nearly constant throughout the soot formation region (the main exceptions are slight reductions of the concentrations of $\mathrm{CH}_{4}$ and $\mathrm{C}_{2} \mathrm{H}_{4}$ in the region $\mathrm{z}=7.5-10.0 \mathrm{~mm}$ ). These results indicate that rates of soot formation in premixed flames (indicated by the variation of soot volume fraction, $\mathrm{f}_{\mathrm{s}}$, with increasing distance from the burner exit), do not decrease due to the consumption of soot forming hydrocarbon species, which is the case for diffusion flames. In contrast, rates of soot formation are seen to progressively decrease in proportion to the decrease of the concentrations of the radical species, $\mathrm{H}$, with increasing distance from the burner exit.

The present determinations of the variation of the number of TEM-observable primary soot particles per unit volume, $n_{\mathrm{p}}$, and the rate of formation of TEM-observable primary soot particles as a function of distance from the burner exit, $w_{\mathrm{n}}$, were similar for premixed flames. ${ }^{28-30}$ The number of TEM-observable primary soot particles per 
cubic meter is seen to increase with increasing distance from the burner exit and then level off in Fig. 2, behaving similar to the variation of the soot volume fraction as a function of distance from the burner exit. Similarly, the rate of formation of TEM-observable primary soot particles per unit volume is largest near the region where soot formation is first observed and then progressively decreases as a function of distance from the burner exit. This behavior is qualitatively similar to the variation of the concentration of the radical species, $\mathrm{H}$, as a function of distance from the burner exit which suggests that soot primary particle nucleation rates are controlled by a mechanism somewhat similar to soot surface growth rates, e.g., the HACA mechanism of soot surface growth. Such a relationship would not be surprising, however, because the formation and growth of the PAH species that are thought to eventually coalesce to form a soot nucleus proceeds by the HACA mechanism. ${ }^{13,14}$ In fact, the similarity of large PAH molecules and the growing surface of TEM-observable primary soot particles (on a local basis), and the corresponding potential similarity of their growth processes, was exploited by Frenklach and coworkers ${ }^{18-20}$ when the HACA mechanism of primary soot particle surface growth was first proposed.

Noting that rates of soot surface growth, which dominate rates of soot formation, ${ }^{11}$ are proportional to the concentration of $\mathrm{H}$ as a first approximation of the HACA mechanisms of soot surface growth, ${ }^{18-20}$ this behavior supports the hypothesis that soot surface growth in premixed flames is dominated by the HACA mechanism. It was also shown that concentrations of $\mathrm{H}$ in the relatively slowly developing post-flame region of premixed sootcontaining flames approximate thermodynamic equilibrium very closely. ${ }^{18-20}$ Thus, the reduction of $\mathrm{H}$ concentrations with increasing streamwise distance observed in Fig. 2 is a direct result of the reduction of the temperature which reduces the equilibrium constant proportional to the yield of $\mathrm{H}$. Recalling that the temperature reduction is largely due to continuum radiation from soot, however, it is evident that increases of the concentration of soot increases radiative heat losses and thus tends to reduce the rate of formation of soot in these flames.

\section{Structure of Diffusion Flames at Atmospheric Pressures}

Measurements of the structure and the TEM-observable primary soot particle nucleation rate properties of laminar diffusion flames at atmospheric pressure are shown in Fig. 3. These flames involve ethylene-fueled flames burning in air at atmospheric pressure. Ethylene was chosen because it was not directly associated with the HACA soot surface growth mechanism. Results for the other diffusion flames, however, were qualitatively similar. ${ }^{31-33}$ In each of these figures, measurements of temperatures, velocities, soot volume fractions, TEM-observable primary soot particle diameters, the concentrations of major gas species, the concentrations of some radical species $(\mathrm{H}, \mathrm{OH}$ and $\mathrm{O}$ ), the number of TEM-observable primary soot particles per unit volume, and the rate of formation of TEMobservable primary soot particles per unit volume are plotted as a function of height above the burner exit. Similar to the flame structure plot for laminar premixed flames illustrated in Fig. 2, corresponding elapsed times found by integrating the velocity measurements are shown at the top of the plots. As before, these elapsed times are relative to the first position where finite soot volume fractions were observed. The right-hand boundaries of Fig. 3 represent the limits of yellow soot luminosity although soot concentrations were too small to be measured accurately as this limit was approached. The flame sheet location, where $\phi=1$ based on measured fuel $(\mathrm{C}$ and $\mathrm{H})$ and oxygen $(\mathrm{O})$ atomic concentrations, are marked on Fig. 3. This illustrates the full range of behavior for soot-containing diffusion flames which includes conditions where soot formation and oxidation are completed at the condition where soot oxidation extends into the fuel-lean region of the flame.

Gas velocities progressively increase from small values of roughly $30 \mathrm{~mm} / \mathrm{s}$ near the burner exit to values in excess of $2000 \mathrm{~mm} / \mathrm{s}$ at the highest position that was measured in Fig. 3 for flames produced by the atmospheric pressure burner that had a relatively large diameter fuel port, indicating significant effects of buoyancy for these flames.

Gas temperatures in Fig. 3 tend to reach a weak maximum significantly smaller than the adiabatic flame temperature of the reactants and well before either the maximum soot concentration or the flame sheet condition $(\phi=1)$ is reached. This behavior is similar to other soot-containing diffusion flames that have been studied in this laboratory and is caused by significant effects of continuum radiation heat losses due to the presence of soot.

Unlike the behavior of premixed flames illustrated in Fig. 2, where TEM-observable primary particle diameters tend to increase proportional to soot volume fractions, TEM-observable primary soot particle diameters in the diffusion flames illustrated in Fig. 3 reach maximum values relatively early in the soot formation region, well before reaching maximum soot volume fraction conditions. This behavior is typical of all observations in the soot formation region of laminar diffusion flames considered in this laboratory. ${ }^{31-33}$ Similar behavior has been observed along the axis of soot-containing laminar diffusion flames by others as well. ${ }^{39,47}$ This behavior is caused by the fact that TEM-observable primary soot particle nucleation rates tend to accelerate with increasing distance in the soot formation region at conditions prior to reaching the maximum TEM-observable primary soot particle diameter in diffusion flames whereas TEM-observable primary soot particle nucleation rates progressively decrease with 
increasing distance in the soot formation region in premixed flames. This behavior causes the relatively few TEMobservable primary soot particles formed near the soot inception condition of diffusion flames, that become large due to lengthy elapsed times for soot surface growth, to be superseded by large numbers of TEM-observable primary soot particles created later in the soot formation period, that are smaller due to smaller elapsed times for soot surface growth.

Notably, it was observed that TEM-observable primary soot particle surface growth remains rapid at soot inception conditions in diffusion flames, where TEM-observable primary soot particle nucleation rates are small, ${ }^{48,49}$ which is consistent with the present observations. In contrast, TEM-observable primary soot particle nucleation rates are largest near the start of the soot formation region in premixed flames and subsequently rapidly decrease with increasing streamwise distance. As a result, most of the TEM-observable primary soot particles form early in the soot formation region of premixed flames with subsequent increases of soot concentrations largely causing increased TEM-observable primary soot particle diameters as a result of TEM-observable primary soot particle surface growth. Finally, it will be seen later that TEM-observable primary soot particle nucleation rates are unusually sensitive to $\mathrm{H}$ concentrations, helping to support the different behavior of TEM-observable primary soot particle diameters in premixed and diffusion flames because the concentrations of $\mathrm{H}$ progressively decrease with increasing streamwise distance in the soot formation region of premixed flames whereas the concentrations of $\mathrm{H}$ progressively increase with increasing streamwise distance in the soot formation region of diffusion flames.

The concentrations of major stable gas species in the diffusion flames illustrated in Fig. 5 are in qualitative agreement with these measurements in premixed flames. ${ }^{28-30}$ When acetylene is the fuel, acetylene concentrations progressively decrease with increasing distance within the soot-containing region. ${ }^{31}$ This behavior extends to other fuels, because the original fuel generally disappears relatively early in the soot formation region, to yield hydrogen and hydrocarbon species that are relatively robust in high-temperature flame environments, particularly acetylene, which is a relatively stable fuel compound at high temperatures. Furthermore, acetylene is especially important as a fuel decomposition product because it is a major building block of $\mathrm{PAH}$, that feeds primary soot particle nucleation, and it also is a major reactant for the HACA soot surface growth mechanism. ${ }^{18-20}$ Thus, due to the rapid decomposition of fuels other than acetylene, concentration distributions of acetylene within flames fueled with hydrocarbons other than acetylene are qualitatively similar to concentration distributions of acetylene in flames fueled with acetylene. ${ }^{32}$ The final combustion products, $\mathrm{CO}_{2}$ and $\mathrm{H}_{2} \mathrm{O}$, increase with increasing streamwise distance throughout the soot formation region, reaching broad maxima near the flame sheet (where $\phi=1$ ). Intermediate combustion products associated with water-gas equilibrium, $\mathrm{CO}$ and $\mathrm{H}_{2}$, are present in relatively large concentrations throughout the soot formation region, reaching broad maxima somewhat upstream of the flame sheet. Finally, nitrogen concentrations remain relatively uniform throughout hydrocarbon diffusion flames burning in air.

Concentrations of $\mathrm{O}_{2}$ either progressively increase as the flame sheet is approached after reaching a broad minimum near the burner exit. This behavior is probably caused by some leakage of coflowing $\mathrm{O}_{2}$ into the fuel-rich region of the flames through the gap between the burner exit and the point where the flames are attached. ${ }^{50}$ Thus, $\mathrm{O}_{2}$ is invariably present at concentrations in the range $0.1-5.0 \%$ (by volume) throughout the soot formation region of the diffusion flames observed during studies of soot processes in diffusion flames. In addition, some fuel-like species, particularly $\mathrm{H}_{2}, \mathrm{CO}$ and soot, penetrate well into the fuel-lean region. Thus, the flames do not accurately satisfy simplified classical ideas about the structure of laminar diffusion flames in that there is considerable overlap of fuellike and oxidant-like species in the region of the flame sheet. Another complication of analysis of flame behavior due to this overlap of fuel and oxidant species is that soot formation and oxidation proceed simultaneously throughout most of the soot-containing region of the flames. Thus, the soot formation region (the region before the maximum soot volume fraction condition is reached) involves conditions where TEM-observable primary soot particle nucleation and surface growth are more important than soot surface oxidation whereas the soot oxidation region (the region after the maximum soot volume fraction condition is reached) involves conditions where soot surface oxidation is more important than TEM-observable primary soot particle nucleation and soot surface growth.

Concentrations of $\mathrm{OH}$ and $\mathrm{O}$ generally increase monotonically with increasing distance from the burner exit throughout the soot-containing region, whereas concentrations of $\mathrm{H}$ reach a broad maximum within the soot formation region before decreasing slightly as the flame sheet is approached. Maximum concentrations of $\mathrm{H}$ and $\mathrm{OH}$ are in the range $0.1-1.0 \%$ by volume, whereas the maximum concentrations of $\mathrm{O}$ are significantly smaller, in the range $0.01-0.1 \%$ by volume. For the atmospheric pressure flames, similar to recent numerical simulations of the structure of soot-containing methane/air and ethylene/air laminar coflowing jet diffusion flames at atmospheric pressure, ${ }^{51}$ near-equilibrium radical concentrations of $\mathrm{OH}$ and $\mathrm{H}$ (based on present measurements of radical and stable species concentrations and the thermochemical data ${ }^{40}$ ) were observed near the onset of soot formation with these concentrations eventually reaching values of 10-20 times larger than equilibrium concentrations near the flame sheet. In addition, concentrations of $\mathrm{O}$ become 100-1000 times larger than equilibrium concentrations as the flame 
sheet is approached for atmospheric pressure flames; nevertheless, as already noted, the concentrations of $\mathrm{O}$ are relatively small everywhere (100-1000 times smaller than $\mathrm{H}$ and $\mathrm{OH}$ concentrations). Finally, as already noted, species that past measurements in soot-containing diffusion flames have shown to be responsible for soot surface growth $\left(\mathrm{C}_{2} \mathrm{H}_{2} \text { and } \mathrm{H}\right)^{31}$ and for soot surface oxidation $\left(\mathrm{OH} \text { and } \mathrm{O}_{2}\right)^{33}$ all are seen to be present within the soot formation region. As a result, soot surface growth and oxidation proceed at the same time in the soot formation regions of the diffusion flames considered during the present investigation.

Present determinations of the number of TEM-observable primary soot particles per unit volume, $\mathrm{n}_{\mathrm{p}}$, and the rates of production of TEM-observable primary soot particles per unit volume, $w_{\mathrm{n}}$, are illustrated at the bottom of Fig. 5. The maximum number of TEM-observable primary soot particles per unit volume is reached on the fuel-rich side of the stoichiometric conditions and slightly at the upstream of the maximum soot volume fraction condition. In contrast, the maximum rate of production of TEM-observable primary soot particles per unit volume, is reached in the region between the maximum primary TEM-observable soot particle diameter and the maximum soot volume fraction conditions. This highlights the effect of the large increases of the number of TEM-observable primary soot particles in the flow on reducing the mean TEM-observable primary soot particle diameter because TEM-observable primary soot particles produced later in the soot formation process have less time for surface growth and thus have smaller diameters than those produced near the soot inception condition. Thus, the tendency for TEM-observable primary particle formation rates to decrease with increasing streamwise distance from the flame sheet for premixed flames, and in contrast for TEM-observable primary particle formation rates to increase with increasing distance toward the flame sheet diameter for diffusion flames, helps explain the differences between the TEM-observable primary soot particle diameter behavior of premixed and nonpremixed flames seen in Figs. 2 and 3.

\section{Structure of Diffusion Flames at 13-811 kPa (0.1-8.0 atm)}

Transmission Electron Microscopy (TEM) photographs of typical soot particles sampled in the flames at $13 \mathrm{kPa}$ $(0.1 \mathrm{~atm})$ and $811 \mathrm{kPa}(8 \mathrm{~atm})$, each obtained at the end of the soot formation region where soot volume fractions are at maximum values, are presented in Fig. 1 (b) and (c). Soot particle images for the present flames were generally similar to TEM images of soot particles obtained in other premixed and diffusion flames. ${ }^{28-35}$ The mean number of primary soot particles per aggregate increased with increasing distance from the burner exit during soot formation period. However, the mean number of primary soot particles per aggregate stayed constant or decreased in the soot oxidation region, which is generally near the tip of the flame.

Measurements of gas (soot) temperatures, streamwise gas velocities, soot volume fractions, primary soot particle diameters, concentrations of major gas species and concentrations of radical species $(\mathrm{H}, \mathrm{OH}, \mathrm{O})$ are plotted as a function of the distance along the axes for the flames at $13 \mathrm{kPa}$ and $811 \mathrm{kPa}$ in Figs. 4 and 5, respectively. The stoichiometric $(\phi=1)$, or flame sheet, conditions locate at $z \sim 36 \mathrm{~mm}$ and are marked on each figure. Luminous flame tips are all at $\mathrm{z}=50 \mathrm{~mm}$ and are near the right-hand boundaries of the figures. These positions also correspond to the location farthest from the burner exit where finite soot volume fractions could be measured.

Gas (soot) temperatures along the flame axes in Figs. 4 and 5 reach a maximum well before the maximum soot concentration and flame sheet conditions are reached. This behavior is similar to other soot-containing laminar jet diffusion flames that have been studied in this laboratory and is caused by continuum radiation heat losses from soot. For helium diluted flames (Fig. 5), the measured gas temperature is lower than for nitrogen diluted flames, which is caused by heat loss due to the helium diffusion that is larger than nitrogen.

The present burner has a relatively small fuel port diameter whereas luminous flame tips are at $50 \mathrm{~mm}$ which are comparable to earlier diffusion flames ${ }^{31-33}$ using a much larger diameter burner port (33 mm as opposed to $3.3 \mathrm{~mm}$ for the present study). As a result, for the flame at pressure of $13 \mathrm{kPa}(0.1 \mathrm{~atm})$, velocities near the burner exit are relatively large, $1-4 \mathrm{~m} / \mathrm{s}$, so that velocities along the flame axis generally decrease with increasing distance from the burner exit, in spite of effects of buoyancy. For the flame at pressure of $811 \mathrm{kPa}(8.0 \mathrm{~atm})$, the initial velocities at the burner tip are less than $1 \mathrm{~m} / \mathrm{s}$ decreasing as ambient pressure increases. However, for the flame at $811 \mathrm{kPa}(8.0 \mathrm{~atm})$, the velocities along the flame axes increase due to buoyancy.

Similar to earlier observations of soot-containing laminar jet diffusion flames, primary soot particle diameters reach maximum values relatively early in the soot formation region. This behavior is caused by accelerating primary soot particle nucleation rates with increasing streamwise distance in the initial portions of the soot formation region, which is caused by progressively increasing $\mathrm{H}$ concentrations with increasing streamwise distance. As a result, the number of primary soot particles increases by 1-2 orders of magnitude between the streamwise positions where the primary particle diameter is a maximum and the soot volume fraction is a maximum. This behavior causes the relatively few primary soot particles formed near soot inception conditions, that become large due to long periods of soot surface growth, to be superseded by the much larger number of primary soot particles formed later in the soot formation region that are smaller due to shorter periods of soot surface growth. This behavior is aided by the fact 
that rates of soot surface growth remain relatively rapid near soot inception conditions, ${ }^{45,46}$ which allows the relatively few primary particles present there to grow quite large.

Significant levels of soot formation (evidenced by the appearance of detectable soot concentrations), were generally associated with the first streamwise locations where detectable concentrations of $\mathrm{H}$ were observed, because acetylene, the other reactant of the HACA soot surface growth mechanisms, was always present near the burner for the present acetylene-fueled flame. Soot formation (as indicated by finite rates of soot surface growth) became small again when maximum soot volume fractions were reached; this occurred in the presence of relatively large concentrations of $\mathrm{H}$ but where acetylene concentrations became smaller than roughly $0.1 \%$ by volume. These conditions for the onset and end of soot formation were also similar to other soot-containing laminar jet diffusion flames that have been studied.

The concentrations of major gas species plotted in Figs. 4 and 5 are generally significantly larger than present limits of detection ( $10 \mathrm{ppm}$ at $811 \mathrm{kPa}$ and ranging up to $200 \mathrm{ppm}$ at a pressure of $13 \mathrm{kPa}$ ); therefore, the appearance and disappearance of particular species on these plots is limited more by spatial resolution than by detection limits. For the flamein Fig. 5, the original fuel is not acetylene. Decomposition of the original fuel in this case, ethylene, yields significant concentrations of acetylene near the burner exit as well. As a result, concentrations of acetylene within flames fueled with hydrocarbons other than acetylene are generally quite similar to acetylene concentrations within acetylene-fueled flames. As the flame sheet ( $\phi=1$ condition) is approached, concentrations of hydrocarbon species decrease and concentrations of the main combustion products $\left(\mathrm{CO}_{2}\right.$ and $\left.\mathrm{H}_{2} \mathrm{O}\right)$ reach broad maxima. In contrast, concentrations of $\mathrm{O}_{2}$ either remain nearly constant at the lower pressures (Fig. 4) at values near 1-2 \% by volume, or gradually increase, in the range $0.01-1 \%$ by volume (at atmospheric pressure), from a broad minimum near the burner exit. This behavior has been observed in all diffusion flames used to study soot surface reaction properties; it is thought to occur due to the presence of $\mathrm{O}_{2}$ at the flame sheet as a result of dissociation and the relatively unreactive behavior of $\mathrm{O}_{2}$ at fuel-rich conditions, evidenced by its rather weak effect on soot surface oxidation rates, as discussed later.

Concentrations of $\mathrm{H}, \mathrm{OH}$, and $\mathrm{O}$ increase as the flame sheet is approached in Figs. 4 and 5 for the flames at the

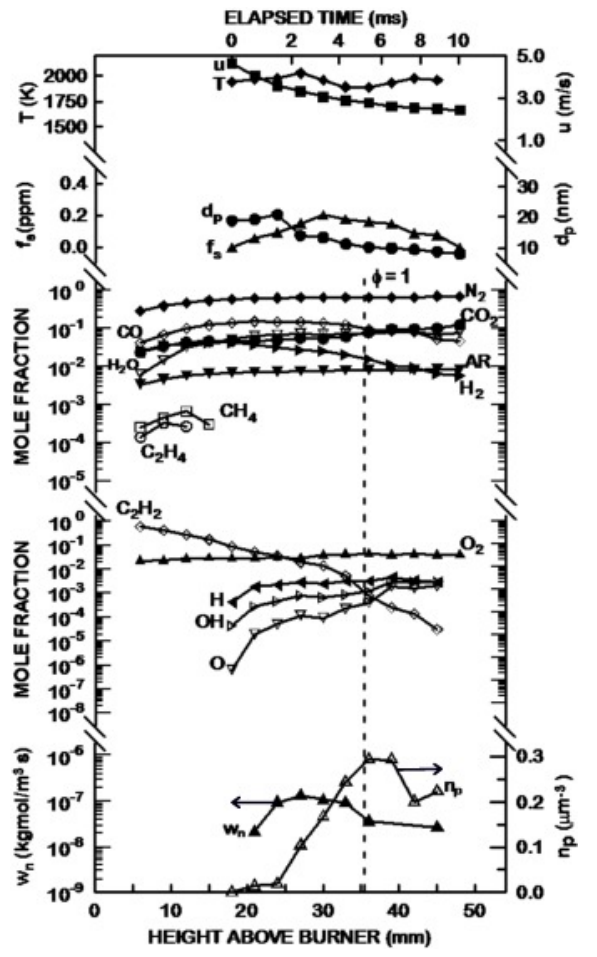

Figure 4. Measured soot, flame and nucleation properties along the axis of an acetylene-fueled laminar jet diffusion flame burning in an air coflow at $13 \mathrm{kPa}(0.125 \mathrm{~atm})$.

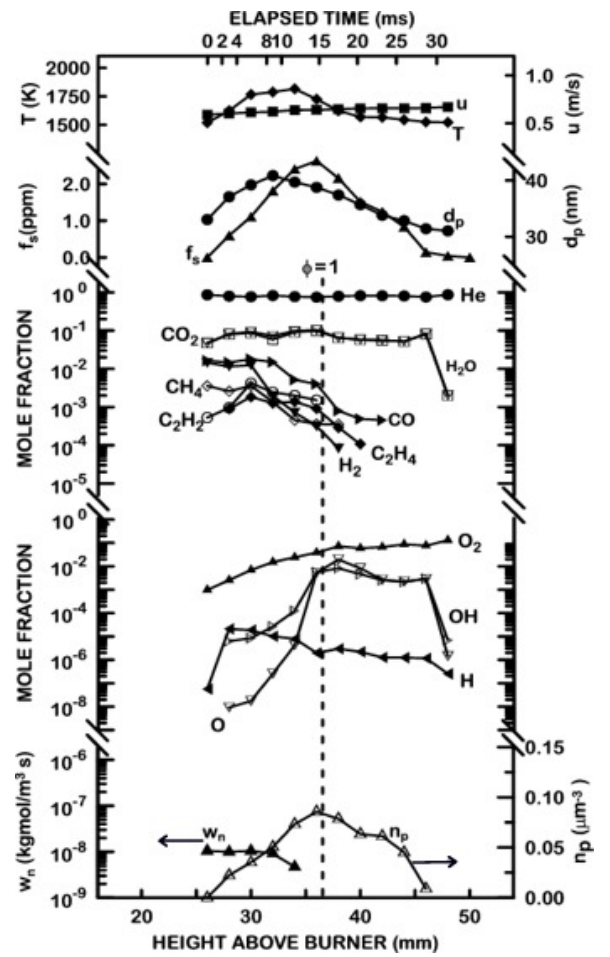

Figure 5. Measured soot, flame and nucleation properties along the axis of an ethylene $(10.2 \%$ by volume)-helium laminar jet diffusion flame burning in oxygen (31.6 \% by volume)-helium coflow at $811 \mathrm{kPa}(8.0 \mathrm{~atm})$. 
pressures of $13 \mathrm{kPa}(0.1 \mathrm{~atm})$. However, radical concentrations are relatively constant or decrease after rapid increase in the initial soot growth region for the flames at the pressure of $811 \mathrm{kPa}(8.0 \mathrm{~atm})$. Generally, these maximum concentrations of $\mathrm{H}$ are roughly 0.1 percent by volume and maximum concentrations of $\mathrm{OH}$ are roughly 0.01 percent by volume, whereas maximum concentrations of $\mathrm{O}$ are significantly smaller. These radical concentrations are similar to values observed in laminar diffusion flames studied for information about soot surface reaction properties at atmospheric pressure. ${ }^{31,32}$

The superequilibrium ratios of $\mathrm{H}, \mathrm{OH}$ and $\mathrm{O}$ were found from the temperatures and compositions measured within the flames, given the equilibrium constant data. ${ }^{47}$ The flame at lower pressure of $13 \mathrm{kPa}(0.1 \mathrm{~atm})$ generally have larger velocities resulting in short elapsed times and larger temperatures caused by reduced radiation heat losses due to the smaller elapsed times. The increased temperature of the flames increases the degree of dissociation of the flame gases and also increases the equilibrium concentrations of radicals. However, the larger velocity does not allow enough time required to establish the equilibrium condition. Therefore, the lower pressure flames generally exhibit larger superequilibrium ratios than the measurements at higher pressures and the earlier measurements of superequilibrium ratios in the soot-containing diffusion flames at atmospheric pressure. ${ }^{31,32}$ On the contrary, the radicals in the flames at higher pressure have relatively longer time to reach the equilibrium condition mainly due to smaller velocities, which enables the superequilibrium ratios lower (closer to equilibrium) than higher velocity flames. In addition, the recombination of radicals, for example, especially $\mathrm{H}+\mathrm{OH}+\mathrm{M}=\mathrm{H}_{2} \mathrm{O}+\mathrm{M}$, is important when the pressure is high. ${ }^{53}$ This mechanism reduces the concentration of radicals at higher pressures and results in lower superequilibrium ratios. It was found that another third-body reaction $\mathrm{H}+\mathrm{O}_{2}+\mathrm{M}=\mathrm{HO}_{2}+\mathrm{M}$ is also important as a chain terminating reaction, ${ }^{54}$ which tends to lower the hydrogen radical concentration especially at the oxidation region at the nominal range of temperature for the flames in this investigation.

\section{B. Soot Surface Reaction Rate Properties}

\section{Soot Surface Growth Rates}

The measurements were used to study soot surface growth rates and primary soot particle nucleation rates in diffusion flames. The major assumptions of this data reduction process were as follows: soot surface growth, rather than primary soot particle nucleation, dominates soot mass production; effects of thermophoresis and diffusive soot motion are small, so that soot particles convect along the flame axis at the local streamwise gas velocity; the soot density is constant; and the surface area available for soot surface growth is equivalent to that of constant diameter spherical primary soot particles that meet at a point. Note that the present assumption of small effects of diffusion (Brownian) on soot is justified due to the large mass of soot particles following their nucleation, and thus small mass diffusivities. Similarly, effects of thermophoresis on soot particle motion are small along the axes of the present flames because streamwise gas velocities are relatively large (on the order of $1 \mathrm{~m} / \mathrm{s}$ ) whereas streamwise temperature gradients are relatively small. In addition, radial thermophoretic velocities are small near the axis of the flames because radial temperature gradients are small in this region due to the axial symmetry of the present test flames. The soot surface growth rate results found in this manner from the present measurements, as well as the use of these measurements to evaluate HACA mechanisms of soot surface growth, are discussed next.

The first soot formation property of importance is the number of primary soot particles per unit volume. This property was found from the measured values of the soot volume fractions and primary particle diameters as follows:

$$
n_{p}=6 f_{s} / \pi d_{p}^{3}
$$

where $f_{\mathrm{s}}$ is the optically determined soot volume fraction and $d_{p}$ is the primary particle diameter measured by thermophoretic sampling and analysis using TEM. The soot surface area per unit volume, $S$, can then be found from these same variables, as follows:

$$
S=\pi d_{p}^{2} n_{p}=6 f_{s} / d_{p}
$$

where the last expression follows from Eq. (1).

Defining the soot surface growth rate, $w_{g}$, as the rate of increase of soot mass per unit area of soot surface and time, conservation of soot mass along a streamline under the previous assumptions yields

$$
w_{g}=(\rho / S) \cdot d\left(\rho_{s} f_{s} / \rho\right) / d t
$$

The gas density in Eq. (3) was found from the present concentration and temperature measurements, assuming an ideal gas mixture of the major gas species and neglecting the volume of soot (which was only present at ppm levels). The soot density $\rho_{s}$ used in Eq. (3) was taken to be $1850 \mathrm{~kg} / \mathrm{m}^{3}$. Finally, the temporal derivative appearing in Eq. (3) was found from three-point least-squares fits of the argument of the derivative $\rho_{s} f_{s} / \rho$. Values of $w_{g}$ were 
corrected for effects of soot surface oxidation, because soot surface growth and surface oxidation proceed at the same time, as noted earlier. Specific methods of estimating rates of soot surface oxidation will be discussed subsequently. However, it should be noted that estimates of effects of soot surface oxidation were carried out, conservatively due to present uncertainties about rates of soot surface oxidation in diffusion flames. In particular, estimates of soot surface growth rates were only considered for conditions where estimates of soot surface oxidation rates were less than half the estimated gross soot surface growth rate. With this approach, consideration of soot surface oxidation was largely limited to finding conditions where soot surface growth rates were relatively large compared to soot surface oxidation rates.

The primary soot particle nucleation rate was defined as the rate of increase of the number of primary soot particles per unit volume and time. This definition is useful because the number of primary soot particles per unit volume is an important observable property of a soot-containing environment that affects the surface area available for soot growth as well as the optical and radiative properties of the flame. Nevertheless, it should be recognized that the present primary soot particle nucleation rate represents a composite of chemical and physical effects, e.g., the various chemical steps that eventually form large molecular weight hydrocarbon molecules as well as the subsequent physical coalescence of these substances to eventually form visible primary soot particles. In addition, the nucleation of primary soot particle only counts for the TEM-observable primary soot particles, which is generally larger than $10 \mathrm{~nm}$.

Based on the same assumptions used to determine soot growth rates from Eq. (3), the expression for primary soot particle nucleation rate is given by:

$$
w_{n}=\rho \cdot d\left(n_{p} / \rho\right) / d t
$$

The temporal derivative in Eq. (4) was found from three-point least-squares fits of the argument of the derivative, $n_{p} / \rho$.

In order to interpret the present soot surface growth rates, gross soot surface growth rates were corrected for effects of soot surface oxidation because soot surface growth and oxidation proceed at the same time as noted in connection with Figs. 2-5. The study of soot surface oxidation included the laminar jet diffusion flames burning in coflowing air at atmospheric pressure. ${ }^{31,32}$ The details of this study will be discussed in next section, however, the results indicated that soot surface oxidation in all these flames proceeded via the $\mathrm{OH}$ soot oxidation mechanism, ${ }^{21,22}$ with nearly the same collision efficiency, after allowing for direct soot surface oxidation based on the $\mathrm{O}_{2}$ oxidation mechanism. ${ }^{23,24}$

Thus, all measurements of soot surface growth considered here were corrected for soot surface oxidation using the $\mathrm{O}_{2}$ and $\mathrm{OH}$ approach developed from the present measurements. It was found that effects of soot surface oxidation estimated in this way were generally small except when soot surface growth rates became small toward the end of the soot-formation region. Thus, in order to be conservative about potential effects of soot surface oxidation, determinations of soot surface growth rates corrected for effects of soot surface oxidation were limited to conditions where estimated soot surface oxidation rates never exceeded half the gross soot surface growth rates.

As an improvement on the simple soot surface growth approach, soot surface growth rates were interpreted using the HACA soot growth mechanisms. ${ }^{18-20}$ These considerations sought to maintain consistency with past evaluations of these mechanisms based on similar measurements. For these considerations the predicted net rate of soot surface growth was expressed, as follows, for both mechanisms:

$$
w_{g}=\alpha_{\mathrm{i}} R_{\mathrm{i}}
$$

where $\mathrm{i}=\mathrm{FW}^{19}$ and $\mathrm{CH}^{20}$ denote reaction parameters for the HACA soot surface growth rate mechanisms. The parameters, $\alpha_{\mathrm{i}}$, are empirical steric factors on order of unity, with $\alpha_{\mathrm{FW}}$ specified to be a function of temperature ${ }^{19}$ and $\alpha_{\mathrm{CH}}$ specified to be a constant. ${ }^{20}$

The $R_{\mathrm{i}}$ in Eq. (5) are proportional to the product $[\mathrm{H}]\left[\mathrm{C}_{2} \mathrm{H}_{2}\right]$ as a first approximation. Thus, $w_{g} /\left[\mathrm{C}_{2} \mathrm{H}_{2}\right]$ measured for all these studies is plotted as a function of $[\mathrm{H}]$ in Fig. 6 , in order to provide a direct test of the main features of the HACA soot growth mechanisms without the intrusion of uncertainties due to the numerous empirical parameters in the original detailed mechanisms. The results for premixed and diffusion flames in Fig. 6 are distinguished by denoting them by open and crossed symbols, respectively. An empirical correlation of the measurements obtained as an average for all flames is surprisingly good and can be expressed as

$$
w_{\mathrm{g}}=2.6 \times 10^{7}\left(\mathrm{~kg} \cdot \mathrm{m}^{4} / \mathrm{kmol} \cdot \mathrm{s}\right)\left[\mathrm{C}_{2} \mathrm{H}_{2}\right][\mathrm{H}]
$$

with uncertainty ( $95 \%$ confidence) of $15 \%$. There is a tendency for $w_{g} /\left[\mathrm{C}_{2} \mathrm{H}_{2}\right]$ to be slightly larger for diffusion flames than for premixed flames, for a given value of $[\mathrm{H}]$, which could be due to slightly overestimated $\mathrm{H}$ concentrations in premixed flames due to the equilibrium assumption made to find $\mathrm{H}$ concentrations for these flames. 
These differences are comparable to the experimental uncertainties (95\% confidence) of the measurements, however, and their statistical significance is questionable. Thus, the correlation of the results according to the approximate HACA mechanism is surprisingly good and soot surface growth rate properties in premixed and diffusion flames are consistent in spite of the fundamental differences between the soot formation environments. Finally, the strong effect of $[\mathrm{H}]$ on $w_{g}$, evident from Fig. 6, combined with the near-equilibrium and strongly super-equilibrium behavior of $\mathrm{H}$ concentrations in premixed and diffusion flames, are responsible for the rather poor correlations.

The corresponding results for the Colket and Hall ${ }^{20}$ soot surface growth mechanism are illustrated in Fig. 7. In this figure, available measurements for both premixed and diffusion flames (after correcting all measurements for soot surface oxidation based on present measurements of soot surface oxidation rates) are illustrated along with bestfit correlation for all the flames. The corresponding steric factor and its experimental uncertainties (95\% confidence) is 0.44 with an uncertainty of 0.11 . First of all, it is encouraging that the steric factor is of order of magnitude unity, as expected. Next, it is evident that use of the Colket and Hall HACA mechanism improves the correlation of soot surface growth rates in Fig. 7, compared to the approximate correlation based on only the leading terms of the HACA mechanisms in Fig. 6. The correlation for the diffusion flames and all the flames is essentially the same. Correlated values of soot surface growth rates for the premixed flames are slightly lower than for the diffusion flames, possibly for reasons already discussed in connection with Fig. 6, but the differences are comparable to present experimental uncertainties. A more direct evaluation of the HACA mechanism of Kazakov et al. ${ }^{19}$ was carried out by plotting $w_{g}$ directly as a function of $\alpha_{\mathrm{FW}} R_{\mathrm{FW}}$ as indicated by Eq. (5) and found to be similar to the result of Colket and Hall mechanism.

The HACA soot surface growth mechanisms ${ }^{18-20}$ continue to be encouraging and they may eventually provide the basis for reliable methods of estimating soot surface growth rates in environments fueled with hydrocarbons. Uncertainties remain, however, about effects of pressure greater than that in current investigation $(8 \mathrm{~atm})$ and about effects of PAH as fuels, on soot surface growth rates in laminar premixed and diffusion flames.

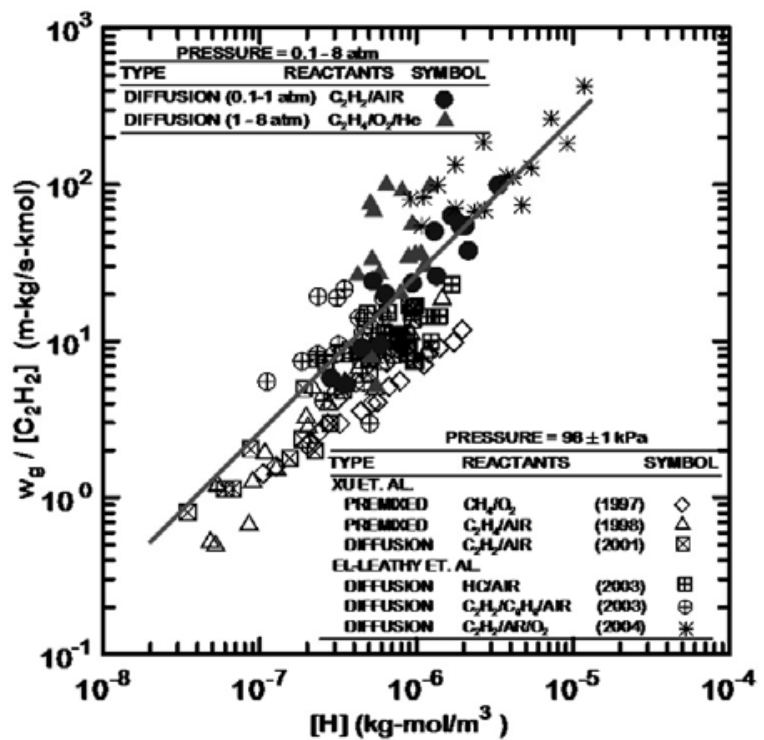

Figure 6. Soot surface growth rates as a function of acetylene and hydrogen atom concentrations for laminar flames at various fuels, flame types, and pressures.

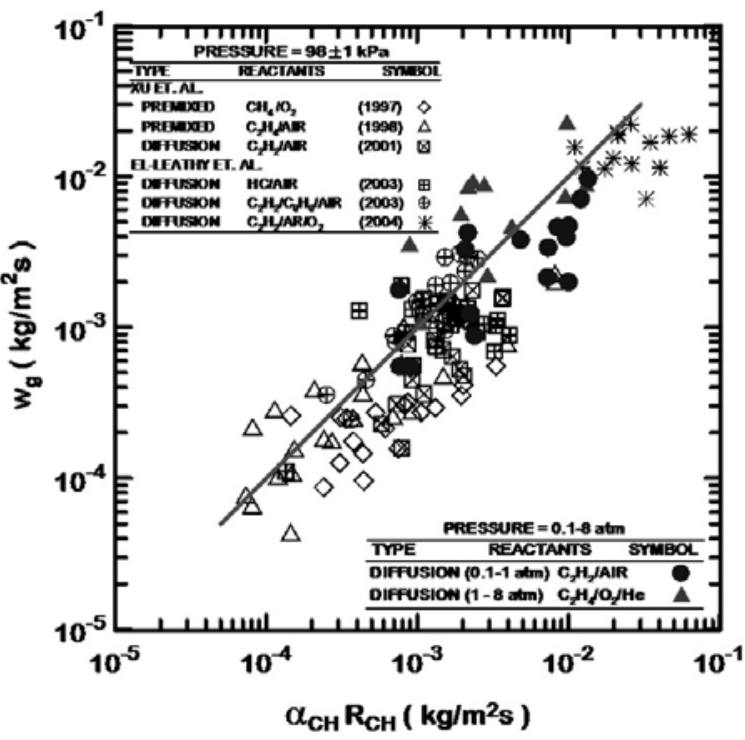

Figure 7. Soot surface growth rates in terms of the HACA mechanism of Colket and Hall $^{20}$ for laminar flames at various fuels, flame types, and pressures.

\section{Soot Surface Oxidation Rates}

The present investigation sought to contribute to better understanding of soot surface oxidation properties in laminar premixed and diffusion flames using various fuels at the pressures of 13-811 kPa (0.1-8.0 atm). Present considerations were limited to the early stages of soot oxidation (carbon consumption less than $70 \%$ ) where reaction at the surface of primary soot particles dominates the process, rather than the later stages where primary soot particle porosity and internal oxidation of the primary soot particles become important. ${ }^{22}$ 
Major assumptions were similar to the earlier studies as follows: soot oxidation occurred only at the surface of primary soot particles, effects of thermophoresis and diffusion (Brownian) on soot motion are small so that soot particles convect on the local streamwise gas velocity, soot density is constant, and the surface area available for soot surface oxidation is equivalent to constant diameter spherical particles that meet at a point. Recall the present measurements were confined to the axes of the flames so that variations of soot properties as a function of time could be obtained directly from the elapsed time determinations.

Conservation of soot mass along a streamline under the present assumptions yields an expression for the soot oxidation rate per unit surface area, $w_{o x}$, as follows:

$$
w_{o x}=-(\rho / S) \cdot d\left(\rho_{s} f_{s} / \rho\right) / d t
$$

where the minus sign is inserted so that $w_{o x}$ is a positive number. The gas density in Eq. (7) was found from measurements of gas species concentrations and temperatures, assuming an ideal gas mixture and neglecting the small volume of soot for present conditions.

Present measurements of soot surface oxidation rates were corrected for effects of soot growth using the expression of simple relationship between soot growth rates and hydrogen and acetylene concentrations as discussed in the previous section, correlated for both premixed and diffusion flame environments. No condition is considered in the following, however, where the estimated correction for soot surface growth was more than half the soot surface oxidation rate.

Present soot surface oxidation rates (corrected for soot surface growth) were converted into collision efficiencies (or reaction probabilities) based on kinetic theory estimates of the collision rates of a given gas species with the surfaces of primary soot particles. Thus, the collision efficiency, $\eta_{\mathrm{i}}$, for a potential oxidizing species, $i$, is given by the following expression:

$$
\eta_{\mathrm{i}}=4 w_{o x} /\left(C_{\mathrm{i}}[\mathrm{i}] \bar{v}_{i}\right)
$$

where

$$
\bar{v}_{i}=\left[8 R_{u} T /\left(\pi M_{i}\right)\right]^{1 / 2}
$$

Values of the $\eta_{i}$ were considered for potential soot surface oxidation by $\mathrm{O}_{2}, \mathrm{CO}_{2}, \mathrm{H}_{2} \mathrm{O}, \mathrm{O}$ and $\mathrm{OH}$.

The collision efficiencies of $\mathrm{O}_{2}$ for soot surface oxidation were evaluated, however, it was found that the Nagle and Strickland-Constable estimates of $\mathrm{O}_{2}$ collision efficiencies are 10-100 times smaller than the measurements in diffusion flames. It strongly suggests that some other species is mainly responsible for soot surface oxidation in diffusion flame environments. Other evidence that $\mathrm{O}_{2}$ is not the main direct soot oxidizing species for flame environments is provided by the large scatter (nearly a factor of 100) of the collision efficiencies. The collision efficiencies of $\mathrm{CO}_{2}, \mathrm{H}_{2} \mathrm{O}$ and $\mathrm{O}$ showed similar scatter, which suggests that other species rather than those are responsible for the soot surface oxidation.

Finally, the collision efficiencies of $\mathrm{OH}$ for soot surface oxidation are plotted as a function of height above the burner in Fig.8. With perhaps one exception (at an extreme condition near a flame tip where experimental uncertainties are relatively large), direct $\mathrm{O}_{2}$ surface oxidation of soot is not very important for the diffusion flames considered in Fig. 8, as before. On the other hand, present collision efficiencies of $\mathrm{OH}$ exhibit relatively small levels of scatter (roughly a factor of 3). Furthermore, the results for premixed and diffusion flames exhibit remarkably good agreement with each other. In particular, the collision efficiency of $\mathrm{OH}$ for soot surface oxidation in the diffusion flames is 0.12 with an experimental uncertainty ( $95 \%$ confidence) of 0.03 or $25 \%$; which is in good agreement with the collision efficiency value of 0.13 for soot surface oxidation in premixed flames ${ }^{21}$ when using the same treatment of soot structure. Finally, this agreement concerning soot surface oxidation by $\mathrm{OH}$ was achieved over a relatively broad range of flame conditions for the combined results in premixed and diffusion flames, as follows: temperatures

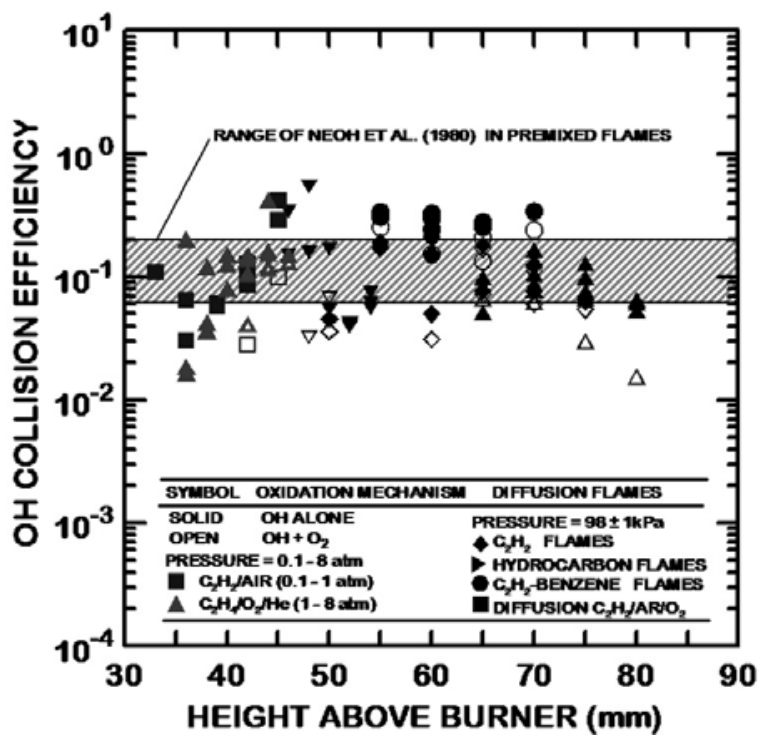

Figure 8. Collision efficiencies assuming soot surface oxidation due to attack by $\mathrm{OH}$ as a function of distance from the burner exit. 
of 1400-2350 K, oxygen mole fractions of $5 \times 10^{-4}-6 \times 10^{-2}$, OH concentrations of $9 \times 10^{-8}-2 \times 10^{-3} \mathrm{kmol} / \mathrm{m}^{3}$, pressures of 13-811 $\mathrm{kPa}(0.1-8.0 \mathrm{~atm})$, and levels of soot mass consumption less than $70 \%$ for flames fueled with a variety of fuels. It is clear that there is no additional effect of pressure on soot surface oxidation in this range.

\section{Conclusion}

Results from the analysis of present measurements when combined with complementary data of previous studies at atmospheric pressure, yield the following conclusions. Note that the range of conditions these conclusions involve considering methane, acetylene, ethylene, propylene, propane and benzene fuels, concentrations of acetylene of $1 \times 10^{-5}-6 \times 10^{-2} \mathrm{kmol} / \mathrm{m}^{3}$, concentrations of $\mathrm{H}$ of $3 \times 10^{-8}-3 \times 10^{-6} \mathrm{kmol} / \mathrm{m}^{3}$, and temperatures of $1400-2350 \mathrm{~K}$ in laminar premixed and diffusion flames.

1. Soot surface growth rates in laminar premixed and diffusion flames are similar, are independent of fuel type, are proportional to $[\mathrm{H}]\left[\mathrm{C}_{2} \mathrm{H}_{2}\right]$, have no significant effect of pressure, and correlate with existing HACA mechanisms having steric factors on the order of unity.

2. Soot surface oxidation rates in laminar premixed and diffusion flames are similar, are independent of fuel type, are dominated by $\mathrm{OH}$ reaction, have no significant effect of pressure, and correlated with the $\mathrm{OH} / \mathrm{O}_{2}$ mechanism with an $\mathrm{OH}$ collision efficiency on the order of 0.1 .

Although this work represents a considerable advance in the fundamental understanding of soot formation and growth processes, additional study of soot nucleation, surface growth and oxidation is needed. In particular, more information about the effects of hydrocarbons, particularly PAH, can further clarify the nucleation and surface growth processes. Direct measurements of PAH concentrations were not made in this work as acetylene was considered the dominant species affecting nucleation and surface growth. However, the conventional HACA mechanisms may need modification, or additional PAH-based growth mechanisms may be required to accurately describe soot surface growth rates at conditions outside the range considered here.

The role of $\mathrm{OH}$ in soot particle oxidation at pressures higher than $10 \mathrm{~atm}$ should be examined, since $\mathrm{OH}$ recombination may reduce the contributions of $\mathrm{OH}$, and $\mathrm{O}_{2}$ oxidation may become more important at higher pressures. Another issue concerning soot oxidation that merits additional study is the effect of internal oxidation of primary soot particles during the final stages of oxidation. For example, after $70 \%$ of the maximum mass of the primary soot particles has been oxidized, the primary soot particles become porous and oxidation within the particles can play a larger role.

Over the pressure range considered here, pressure effects on soot formation and oxidation processes were well captured by existing theory. However, at the higher pressures found in many practical combustion devices, the high particle densities may significantly alter the mechanisms important in soot formation and oxidation. Reliable experimental results for soot surface reaction properties at higher pressures than those considered here require a new technical approach, since flames at higher pressures become turbulent due to buoyant forces and they become optically thick. Nevertheless, such challenging investigations of soot properties at higher pressures will help clarify our understanding of soot formation at conditions directly relevant to numerous practical combustion systems.

\section{Acknowledgments}

This research was financially supported by NASA Grants NCC3-661, NAG3-1245, NAG3-1878, NAG3-2048 and NAG3-2404 under the technical management of Drs. D. L. Urban and Z.-G. Yuan of the NASA Glenn Research Center and Naval Research Grant No. N00014-93-0321 under the technical management of G. D. Roy.

\section{References}

${ }^{1}$ Müller, B., Seifart, C. and Barth, P. J. (1998) "Effect of Air Pollutants on the Pulmonary Surfactant System," European Journal of Clinical Inverstigation, Vol. 28, pp. 762-777.

${ }^{2}$ Tien, C. L. and Lee, S. C. (1982) "Flame Radiation," Progress in Energy and Combustion Science, Vol. 8, pp. 41-59.

${ }^{3}$ Köylü, Ü. Ö. and Faeth, G. M. (1991) "Carbon Monoxide and Soot Emissions from Liquid-Fueled Buoyant Turbulent Diffusion Flames," Combustion and Flame, Vol. 87, No. 1, pp. 61-76.

${ }^{4}$ Köylü, Ü. Ö., Sivathanu, Y. R. and Faeth, G. M. (1991) "Carbon Monoxide Emissions from Buoyant Turbulent Diffusion Flames," Third International Symposium on Fire Safety Science, Elsevier, London, pp. 625-634.

${ }^{5}$ Viskanta, R. and Mengüc, M. P. (1987) "Radiation Heat Transfer in Combustion Systems," Progress in Energy and Combustion Science, Vol. 13, No. 2, pp. 97-160. 
${ }^{6}$ Ramanathan, V., Chung, C., Kim, D., Bettge, T., Buja, L., Kiehl, J. T., Washington, W. M., Fu, Q., Sikka, D. R. and Wild, M. (2005) "Atmospheric brown clouds: Impacts on South Asian Climate and Hydrological Cycle," Proceedings of the National Academy of Sciences, Vol. 102, No. 15, pp. 5326-5333.

${ }^{7}$ Hansen, J. and Nazarenko, L. (2004) "Soot Climate Forcing via Snow and Ice Albedos," Proceedings of the National Academy of Sciences, Vol. 101, No. 2, pp. 423-428.

${ }^{8}$ Ramanathan, V., Crutzen, P. J., Kiehl, J. T. and Rosenfeld, D. (2001) "Aerosols, Climate, and the Hydrological Cycle," Science, Vol. 294, pp. 2119-2124.

${ }^{9}$ Menon, S., Hansen, J., Nazarenko, L. and Luo Y. (2002) "Climate Effects of Black Carbon Aerosols in China and India," Science, Vol. 297, pp. 2250-2253.

${ }^{10}$ Hansen, J. and Sato, M. (2004) "Greenhouse gas growth rates," Proceedings of the National Academy of Sciences, Vol. 101, No. 46, pp. 16109-16114.

${ }^{11}$ Harris, S. J. and Weiner, A. M. (1983) "Surface Growth of Soot Particles in Premixed Ethylene/Air Flames," Combustion Science and Technology, Vol. 31, Nos. 3 and 4, pp. 155-167.

${ }^{12}$ Haynes, B. S. and Wagner, H. G. (1981) "Soot Formation," Progress in Energy and Combustion Science, Vol. 7, No. 4, pp. 229-273.

${ }^{13}$ Howard, J. B. (1990) "Carbon Addition and Oxidation Reactions in Heterogeneous Combustion and Soot Formation," Proceedings of the Combustion Institute, Vol. 23, pp. 1107-1127.

${ }^{14}$ Richter, H., and Howard, J.B. (2000) "Formation of Polycyclic Aromatic Hydrocarbons and their Growth to Soot- A Review of Chemical Reaction Pathways," Progress in Energy and Combustion Science, Vol. 26, pp. 565608 .

15 Sunderland, P. B. and Faeth, G. M. (1996) "Soot Formation in Hydrocarbon/Air Laminar Jet Diffusion Flames," Combustion and Flame, Vol. 105, No. 1/2, pp. 132-146.

${ }^{16}$ Sunderland, P. B., Köylü, Ü. Ö. and Faeth, G. M. (1995) "Soot Formation in Weakly-Buoyant AcetyleneFueled Laminar Jet Diffusion Flames Burning in Air," Combustion and Flame, Vol. 100, No. 1/2, pp. 310-322.

${ }^{17}$ Lin, K. -C, Sunderland, P. B. and Faeth, G. M. (1996) "Soot Nucleation and Growth in Acetylene/Air Laminar Coflowing Jet Diffusion Flames," Combustion and Flame, Vol. 104, No. 3, pp. 369-375.

${ }^{18}$ Frenklach, M. and Wang, H. (1994) "Detailed Mechanism and Modeling of Soot Particle Formation," Soot Formation in Combustion (H. Bockhorn, ed.), Springer-Verlag, Berlin, pp. 165-192.

${ }^{19}$ Kazakov, A., Wang, H. and Frenklach, M. (1995) "Detailed Modeling of Soot Formation in Laminar Premixed Ethylene Flames at a Pressure of 10 Bar," Combustion and Flame, Vol. 100, No. 1/2 , pp. 111-120.

${ }^{20}$ Colket, M. B. and Hall, R. J. (1994) "Success and Uncertainties in Modeling Soot Formation in Laminar Premixed Flames," Soot Formation in Combustion (H. Bockhorn. ed.), Sprinter-Verlag, Berlin, pp. $442-470$.

${ }^{21}$ Neoh, K. G., Howard, J. B. and Sarofim, A. F. (1980) "Soot Oxidation in Flames," Particulate Carbon (Siegla, D. C. and Smith, G. W., eds.), Plenum Press, New York, pp. 261-277.

${ }^{22}$ Neoh, K. G., Howard, J. B. and Sarofim, A. F. (1984) "Effect of Oxidation on the Physical Structure of Soot," Proceedings of the Combustion Institute, Vol. 20, pp. 951-957.

${ }^{23}$ Nagle, J. and Strickland-Constable, R. F. (1962) “Oxidation of Carbon between 1000-2000 ${ }^{\circ}$ C,” Proceedings of 5 th Carbon Conference, Vol. 1, pp. 154-164.

${ }^{24}$ Park, C. and Appleton, J. P. (1973) "Shock-Tube Measurements of Soot Oxidation Rates," Combustion and Flame, Vol. 20, pp. 369-379.

${ }^{25}$ Garo, A., Lahaye, J. and Prado, G. (1986) "Mechanisms of Formation and Destruction of Soot Particles in a Laminar Methane-Air Diffusion Flame," Proceedings of the Combustion Institute, Vol. 21, pp. 1023-1031.

${ }^{26}$ Garo, A., Prado, G. and Lahaye, J. (1990) "Chemical Aspects of Soot Particles in a Laminar Methane-Air Diffusion Flame," Combustion and Flame, Vol. 79, pp. 226-233.

27 Hardiquert, M., Cessou, A., Stepowski, D. and Coppalle, A. (1997) "OH and Soot Concentration Measurements in a High-Temperature Laminar Diffusion Flame," Combustion and Flame, Vol. 111, pp. 338-349.

${ }^{28}$ Xu, F., Sunderland, P. B., and Faeth, G. M. (1997) "Soot Formation in Laminar Premixed Ethylene/Air Flames at Atmospheric Pressure," Combustion and Flame, Vol. 108, pp. 471-493.

${ }^{29}$ Xu, F., Lin, K. -C., and Faeth, G. M. (1998) "Soot Formation in Laminar Premixed Methane/Oxygen Flames at Atmospheric Pressure," Combustion and Flame, Vol. 115, pp. 195-209.

${ }^{30}$ Xu, F. and Faeth, G.M. (2000) "Structure of the Soot Growth Region of Laminar Premixed Methane/Oxygen Flames," Combustion and Flame, Vol. 121, pp. 640-650.

${ }^{31} \mathrm{Xu}, \mathrm{F}$. and Faeth, G.M. (2001) "Soot Formation in Laminar Acetylene/Air Diffusion Flames at Atmospheric Pressure," Combustion and Flame, Vol. 125, pp. 804-819.

32 El-Leathy, A. M., Xu, F., Kim, C. H., and Faeth, G. M. (2003) "Soot Surface Growth in Laminar Hydrocarbon/Air Diffusion Flames," AIAA Journal, Vol. 41, pp. 856-865. 
33 El-Leathy, A. M., Kim, C. H., Faeth, G. M., and Xu, F. (2004) "Structure and Soot Surface Reaction Properties of High Temperature Diffusion Flames at Atmospheric Pressure" AIAA Journal, Vol. 42, No. 5, pp. 988996.

${ }^{34}$ Kim, C. H., El-Leathy, A. M., Xu, F. and Faeth, G. M. (2004) "Soot Surface Growth and Oxidation in Laminar Diffusion Flames at Pressures of 0.1-1.0 atm," Combustion and Flame, Vol. 136, pp.191-207.

${ }^{35}$ Kim, C. H., Xu, F. and Faeth, G. M. (2006) "Soot Surface Growth and Oxidation in Laminar Diffusion Flames at Pressures of 101-811 kPa," in preparation.

${ }^{36}$ Dalzell, W. H. and Sarofim, A. F. (1969) "Optical Constants of Soot and Their Application to Heat Flux Calculations," Journal of Heat Transfer, Vol. 91, No. 1, pp. 100-104.

${ }^{37}$ Krishnan, S. S., Lin, K.C. and Faeth, G. M. (2000) "Optical Properties in the Visible of Overfire Soot in Large Buoyant Turbulent Diffusion Flames," Journal of Heat Transfer, Vol. 122, pp. 517-524.

${ }^{38}$ Krishnan, S. S., Lin, K.C. and Faeth, G. M. (2001) "Extinction and Scattering Properties of Soot Emitted from Large Buoyant Turbulent Diffusion Flames,” Journal of Heat Transfer, Vol. 123, pp. 331-339.

${ }^{39}$ Dobbins, R. A. and Megaridis, C. M. (1987) "Morphology of Flame-Generated Soot as Determined by Thermophoretic Sampling," Langmuir, Vol. 3, No.2, pp. 254-259.

${ }^{40}$ Chase, M.W., Jr., Davies, C.A., Downey, J.R., Jr., Frurip, D.J., McDonald, R.A. and Syverud, A.N. (1986) "JANAF Thermochemical Tables," $3^{\text {rd }}$ ed., Journal of Physical Chemistry Reference Data, Vol. 14, Supplement No. 1, p. 1211.

${ }^{41}$ Ramer, E. R., Merklin, J. F., Sorensen, C. M. and Taylor, T. W. (1986) "Chemical and Optical Probing of Premixed Methane/Oxygen Flames," Combustion Science and Technology, Vol. 48, Nos. 5 and 6, pp. $241-255$.

${ }^{42}$ Hamins, A., Gordon, S., Saito, K. and Seshadri, K. (1986) "Study of Soot Formation in Laminar Coflow-Air $\mathrm{C}_{2}$ Diffusion Flames.," Combustion Science and Technology, Vol. 45, pp. 309-310.

${ }^{43}$ Colket, M. B., Seery, III, D., J., and Palmer, H. B. (1989) "The Pyrolysis of Acetylene Initiated by Acetone," Combustion and Flame, Vol. 75, pp. 343-366.

${ }^{44}$ Colket, M. B., Seery, III, D., J., and Palmer, H. B. (1991) "On Impurity Effects in Acetylene Pyrolysis," Combustion and Flame, Vol. 84, pp. 434-437.

45 Köylü, Ü. Ö., Faeth, G. M., Farias, T. L. and Carvalho, M. G. (1995) "Fractal and Projected Structure Properties of Soot Aggregates," Combustion and Flame, Vol. 100, pp. 621-633.

${ }^{46}$ Benish, T. G., Lafleur, A. L., Taghizadeh, K., and Howard, J. B. (1996) " $\mathrm{C}_{2} \mathrm{H}_{2}$ and PAH as Soot Growth Reactants in Premixed $\mathrm{C}_{2} \mathrm{H}_{4}$-Air Flames," Proceedings of the Combustion Institute, Vol. 26, pp. 2319-2326.

${ }^{47}$ Dobbins, R. A., Fletcher, R. A., and H., -C., Chang (1998) "The Evolution of Soot Precursor Particles in a Diffusion Flame," Combustion and Flame, Vol. 115, pp. 285-298.

48 Tesner, P.A., (1958) "Formation of Dispersed Carbon by Thermal Decomposition of Hydrocarbons," Proceedings of the Combustion Institute, Vol. 7, pp. 546-556.

49 Tesner, P.A. (1960) "Dispersed Carbon Formation by Acetylene Self-Combustion," Proceedings of the Combustion Institute, Vol. 8, pp. 627-633.

${ }^{50}$ Mitchell, R. E., Sarofim, A. F. and Clomberg, L. A. (1980) "Experimental and Numerical Investigation of Confined Laminar Diffusion Flames," Combustion and Flame, Vol. 37, pp. 227-244.

${ }^{51}$ Smooke, M. D., McEnally, C. S., Pfefferle, L. D., Hall, D. J. and Colket, M. B. (1999) "Computational and Experimental Study of Soot formation in a Coflow, Laminar Diffusion Flame,” Combustion and Flame, Vol. 117, pp. 117-139.

52 Chase, M.W., Jr., Davies, C.A., Downey, J.R., Jr., Frurip, D.J., McDonald, R.A. and Syverud, A.N. (1986) “JANAF Thermochemical Tables," $3^{\text {rd }}$ ed., Journal of Physical Chemistry Reference Data, Vol. 14, Supplement No. 1, p. 1211.

${ }^{53}$ Li, J., Zhao, Z., Kazakov, A., Dryer, F. L., (2004) “An updated comprehensive kinetic model of hydrogen combustion," International Journal of Chemcal Kinetics, Vol. 36, pp. 566-575.

${ }^{54}$ Michael, J. V., Su, M. C., Sutherland, J. W., Carroll, J. J., Wagner, A. F. (2002), "Rate Constants For $\mathrm{H}^{+} \mathrm{O}_{2}+$ $\mathrm{M} \rightarrow \mathrm{HO}_{2}+\mathrm{M}$ in Seven Bath Gases," Journal of Physical Chemistry, A. Vol. 106, pp. 5297-5313 